От редакции: автор статьи В.Н. Титов - известный ученый, работающий в крупном учреждении, предлагает свою концепцию формирования инсулинорезистентности как филогенетически обусловленного интегрального патофизиологического состояния вследствие нарушения биологических функций и активации биологических реакций, формирование которых в филогенезе произошло ранее функции локомоции и системы инсулина. В отличие от этого гибкого патофизиологического механизма, по мнению автора, под сахарным диабетом 2 типа следует понимать те состояния, которые в настоящее время обозначают как ДРУГИЕ типы диабета (диабет МОDY, аномалии рецепторов, диабет при гликогенозе). Хотя в настоящее время сложно себе представить клиническое воплощение изложенных автором идей, тем не менее, его научная гипотеза может заинтересовать читателей журнала.

\title{
B.Н. Титов
}

ФГБУ «Российский кардиологический научно-производственный комплекс» Минздравсоцразвития России, Москва

\section{Становление в филогенезе, этиология и патогенез синдрома резистентости к инсулину. Отличия от сахарного диабета второго типа}

\begin{abstract}
Этиологическим фактором резистентности к инсулину мы считаем позднее формирование инсулина на ступенях филогенеза и его узкую функциональную направленность - обеспечение субстратами энергии биологической функции локомоции, только функции движения. Согласно биологической субординации, инсулин не в силах изменить ту регуляцию, которая сформировалось на ранних ступенях филогенеза во всех клетках, в том числе и в инсулинзависимых; таковыми в филогенезе они стали позднее. Это относится а) к механизмам $\beta$-окисления жирных кислот в митохондриях; б) синтезу С 16:0 пальмитиновой насыщенной жирной кислоты; в) метаболизму глюкозы у про- и эукариот; г) регуляции биохимических реакций в инсулиннезависимых клетках; д) гуморальному действию медиаторов на уровне паракринныхх сообществ клеток - структурных и функциональных единии всех органов и е) гормональной регуляции метаболизма на уровне организма. Патогенетическими факторами резистентности к инсулину являются биохимические и функциональные нарушения, которые происходят іп vivo при активации биологических функций и биологических реакций, сформировавшихся в филогенезе ранее, чем инсулин. На ступенях филогенеза система инсулина органично надстроилась над регуляторными механизмами митохондрий, ранних одноклеточных и регулящией в паракринных сообществах клеток.Со всеми ними инсулин функционально взаимодействует, однако отменить действие ни одного из филогенетически ранних гуморальных медиаторов не может. Резистентность к инсулину - патофизиологичное функциональное несоответствие гуморальной регуляции метаболизма на уровне филогенетически ранних паракринных сообществ клеток и более позднего организма, а также последовательного становления в филогенезе вначале пассивного поглощения клетками жирных кислот в форме неэтерифицированных жирных кислот и позже - в форме триглицеридов. Резистентность к инсулину, если она обусловлена нарушениями в первичной структуре белков переноса, депонирования глюкозы и рецепции инсулина в клетке, - это сахарный диабет второго типа.

Ключевые слова: инсулин, резистентность к инсулину, глюкоза, жирные кислоты, филогенез.
\end{abstract}

V.N. Titov

Russian Cardiology Research-and-Production Center, Ministry of Health, Moscow, Russia

\section{Phylogenesis, etiology and pathogenesis of insulin resistance. Differences from type ii diabetes mellitus}

We believe that etiological factor of insulin resistance is phylogenetically late formation of insulin and its specific functionality, i.e., providing energy substrates for the biological function of locomotion. According to biological subordination, insulin cannot change regulation formed at the early stages of phylogenesis in all cells, including those that become insulin-dependent at the late stages of phylogenesis. This involves a) $\beta$-oxidation of fatty acids in the mitochondria, b) synthesis of $C$ 16:0 palmitic saturated fatty acid, c) glucose metabolism in pro-and eukaryotes, $d$ ) regulation of biochemical reactions in insulin-independent cells, e) humoral effects of mediators at the level of paracrine cell communities which are structural and functional units of all internal organs, and f) hormonal regulation at the entire organism level. Pathogenetic factors of insulin resistance are biochemical and functional disorders occurring in vivo upon activation of biological functions and reactions that formed phylogenetically earlier than insulin. During phylogenesis the insulin system has intrinsically built up over the regulatory mechanisms of mitochondria, early unicellular organisms and paracrine cell communities. Insulin functionally interacts with them all, but it cannot abolish the effects of any phylogenetically earlier humoral mediator. Insulin resistance is a pathophysiological disparity between humoral regulation of metabolism at the level of phylogenetically earlier paracrine cell communities and at the level of phylogenetically late total organism, on the one hand, and successive phylogenetic formation of passive cellular uptake of fatty acids as unesterified fatty acids and later triglycerides, on the other. If insulin resistance results from changes in the primary structure of transport proteins, in glucose storage and cellular insulin reception, it can be referred to as type II diabetes mellitus. Key words: insulin, insulin resistance, glucose, fatty acids, phylogenesis. 
Резистентность к инсулину (РИ) - состояние пониженной чувствительности периферических тканей к биологическому, регуляторному действию гормона. Развивается РИ не только при сахарном диабете второго типа, но и при иных заболеваниях, которые сопровождают нарушения метаболизма [1]. В литературе рассмотрена роль РИ в патогенезе сахарного диабета второго типа [2]; описана патофизиология, клинические проявления и подходы к ее лечению [3, 4]. Данные о РИ при сахарном диабете второго типа охарактеризованы и как нарушение метаболического ответа на эндо- и экзогенный инсулин (ИНС). РИ развивается и вне сахарного диабета второго типа: это происходит при ожирении [5]; метаболическом синдроме [6]; при врожденных формах гиперлипопротеинемии (ГЛП) с высоким содержанием триглицеридов (ТГ) [7]; при неалкогольной жировой болезни печени [8]; избытке в пище пальмитиновой насыщенной жирной кислоты (Пальм н-ЖК) [9] и гиперсекреции предсердного натрийуретического пептида.

Мы полагаем, что РИ - функциональное патофизиологичное состояние, когда при отсутствии нарушений в функции системы ИНС реализации действия гормона «мешают» иные регуляторные факторы, которые филогенетически сформировались раньше, до начала синтеза и функционирования ИНС. Если действие ИНС нарушено по причине, к примеру, врожденного дефекта в каскаде передач сигнала ИНС от рецептора в клетку, это, мы полагаем, не РИ, а диабет второго типа. Вероятно, различие РИ и диабета второго типа состоит в том, что РИ - состояние сугубо функциональное; это нарушение взаимоотношения гуморальных медиаторов на разных уровнях регуляции in vivo; структурно же обусловленная РИ - это диабет второго типа.

Этиологическим фактором диабета второго типа являются врожденные ошибки метаболизма: а) нарушения первичной структуры в полипептидных цепях белков, которые задействованы в поглощении клетками глюкозы (ГЛЮ) через глюкозные транспортеры (ГЛЮТ), включая инсулинзависимые ГЛЮТ4; б) метаболические превращения ГЛЮ в клетках; в) на путях депонирования ГЛЮ в форме гликогена и ее освобождения при гликогенолизе; г) нарушения рецепции ИНС и цепи первичных и вторичных посредников передачи гормонального сигнала от рецептора к исполнительным системам в инсулинзависимых клетках, заканчивая синтезом циклического аденозинмонофосфата. При этом синтез, депонирование и секреция ИНС $\beta$-клетками островков не нарушены.

Этиологическим фактором РИ по всей видимости служит позднее формирование ИНС на ступенях филогенеза и его узкая функциональная направленность обеспечение субстратами энергии наиболее поздней биологической, соматической функции локомоции, а именно - функции движения. Согласно описанному нами ранее методологическому приему биологической субординации [10], ИНС «не в силах» изменить то, что сформировано на более ранних ступенях филогенеза во всех клетках, в том числе и в инсулинзависимых, которые стали таковыми в филогенезе относительно поздно. Это относится а) к механизмам $\beta$-окисления митохондриями клеток ЖК, регуляция которого заложена еще в геноме митохондрий у архибактерий; б) синтезу С 16:0 Пальм н-ЖК и метаболическим превращениям ГЛЮ у про- и эукариот; в) регуляции биохимических реакций в инсулиннезависимых клетках; г) гуморальном действии медиаторов на уровне паракринных сообществ клеток - структурных и функциональных единиц каждого из органов; д) гормональной регуляции метаболизма на уровне организма.

Патогенетическими факторами РИ являются биохимические и функциональные нарушения, которые происходят in vivo при активации биологических функций и биологических реакций, которые сформировались в филогенезе ранее, чем биологическая функция локомоции и система ИНС. В процессе филогенеза система ИНС органично надстроилась над регуляторными механизмами митохондрий, ранних одноклеточных и паракринных сообществ клеток. Со всеми из них ИНС функционально взаимодействует, однако отменить действие ни одного из филогенетически ранних гуморальных медиаторов ИНС не может. Каковы же биологические функции и биологические реакции, нарушение функционального состояния (активация) которых приводит к формированию инсулинзависимыми клетками физиологического или патофизиологичного состояния РЕ3 к гормону?

РИ может быть физиологичной; скелетные миоциты используя ГЛЮТ4 и действие ИНС, поглотили максимальное количество ГЛЮ, синтезировали возможное содержание гликогена и ТГ. Однако в межклеточной среде сохраняется гипергликемия, гиперинсулинемия и условия для продолжения пассивного поглощения клетками ГЛЮ. В такой ситуации скелетные миоциты, руководствуясь аутокринной регуляцией, «убирают» с мембраны ГЛЮТ4 и формируют функциональную, физиологичную РИ. Она не бывает длительной; как только миоциты сделают несколько сокращений, и количество гликогена в цитозоле станет меньше, миоциты, на принципах той же аутокринии «выставят» на клеточную мембрану ГЛЮТ4, депонированные в цитозоле вместе с фрагментами плазматической мембраны в форме кольцевых структур. Чем больше число скелетных миоцитов, чем выше уровень физической активности, тем реже формируются условия РИ. В филогенезе, в соответствии с методологическим приемом биологической субординации, клетки осуществляют следующие действия.

- В первую очередь, реализуют гуморальные стимулы филогенетически самой ранней аутокринной регуляции [11].

- Далее происходит исполнение действия гуморальных медиаторов на уровне паракринной регуляции в сообществах клеток при действии филогенетически ранних медиаторов эйкозаноидов, гормонов (тиреоидные гормоны, гормон роста, глюкокортикоиды, катехоламины и эстрогены).

- И только после этого очередь доходит до реализации действия филогенетически позднего ИНС, причем только в инсулинзависимых клетках. Указанная последовательность реализации клетками действия гуморальных медиаторов, вероятнее всего, и составляет основу патогенеза РИ. In vivo не существует ни одного гормона, действие которого не было бы вначале отработано на уровне филогенетически ранних паракринных сообществ клеток, а только затем на уровне организма. Активация каждого из филогенетически ранних регуляторных медиаторов in vivo и является тем фактором, который не дает ИНС возможности проявить свое действие.

Развитие одно- и многоклеточных организмов происходило путем совершенствования на ступенях филогенеза биологических функций. Столь же медленно и параллельно в филогенезе происходило формирование и патологических процессов. По нашему мнению, если 
частота заболеваемости в популяции превышает 5-7\%, то а) основу патогенеза составляет нарушение биологических функций и биологических реакций, и б) патогенез каждой из нозологических форм заболеваний рационально выстраивать в аспекте эволюционного развития. Мы считаем обоснованным рассматривать становление патологии одновременно со становлением в филогенезе биологических функций и биологических реакций. В течение нескольких миллиардов лет на ступенях филогенеза формировались:

- биологическая функция трофологии, функция питания;

- биологическая функция гомеостаза;

- биологическая функция эндоэкологии - «чистоты» межклеточной среды;

- биологическая функция адаптации;

- биологическая функция продолжения вида;

- биологическая функция локомоции;

- биологическая функция интеллекта, когнитивная функция.

Биологическая функция трофологии состоит из двух биологических реакций: реакция экзотрофии (внешнего питания) и эндотрофии. Поскольку физиологично секреция $\beta$-клетками ИНС происходит только при приеме пищи, РИ относится к патологии биологической реакции экзотрофии, а ожирение - к нарушениям биологической реакции эндотрофии. Биологическая функция гомеостаза включает десятки биохимических реакций и физико-химических процессов, которые не допускают снижения ни одного из показателей межклеточной среды in vivo ниже нижнего физиологичного предела. Биологическая функция эндоэкологии - поддержание «чистоты» межклеточной среды - не допускает превышения ни одним из параметров (аналитов) верхней границы физиологичного интервала. Любой из аналитов в повышенной концентрации in vivo оценивается как биологический «мусор», который подлежит удалению или утилизации. Биологическим «мусором» становится и ГЛЮ при гипергликемии. Удаление малого «мусора» с молекулярной массой менее 70 кДа (молекулярная масса альбумина) осуществляет биологическая реакция экскреции путем фильтрации через мембрану гломерул и удаления с мочой. За удаление и утилизацию большого «мусора» (более 70 кДа) ответственна биологическая реакция воспаления, путем фагоцитоза оседлыми макрофагами в локальном пуле клеток рыхлой соединительной ткани (РСТ), интерстициальной ткани. Сочетанно с воспалением и экскрецией, биологическую функцию эндоэкологии реализуют биологические реакции гидродинамического (артериального) давления, реакция трансцитоза и биологическая реакция гипертермии. Биологическую функцию адаптации реализуют биологические реакции стресса, биологическая реакция компенсации и синдром компенсаторного противовоспалительного ответа. Становление биологических функций на ступенях филогенеза происходило не одновременно; между этими этапами порой проходили сотни миллионов лет. Среди соматических биологических функций функция локомоции является наиболее поздней, а ИНС наиболее поздним из гормонов. Параллельно каждой из биологических функций столь же длительно формировались и условия (предпосылки) патологии биологических функций и биологических реакций.

Первой и наиболее частой причиной РИ является нарушение биологической функции трофологии. Оно многообразно и включает: а) избыточное содержание в пище Пальм н-ЖК; б) алиментарный дефицит эссенциальных полиеновых ЖК (ЭС поли-ЖК); в) избыток в пище углеводов. В филогенезе, при становлении систем переноса ЖК в форме липидов в составе разных классов липопротеинов (ЛП), в водах третьего океана, содержание Пальм н-ЖК в пище не превышало $15 \%$ всех ЖК, и в пище было много ЭС поли-ЖК. В указанных условиях и сформировалась система переноса и поглощения клетками ЖК в форме липидов в составе ЛП, а также регуляция метаболизма ЖК. При малом содержании в пище н-ЖК, низком уровне экспрессии генов ферментов превращения Пальм н-ЖК в олеиновую ЖК (пальмитоилэлонгазы и стеароилдесатуразы) в течение миллионов лет было достаточно. Ферменты осуществляли синтез по пути С 16:0 Пальм н-ЖК $\rightarrow$ C 18:0 стеариновая н-ЖК $\rightarrow$ С 18:1 олеиновая моноеновая (моно) ЖК. В физиологичных условиях, при низком содержании Пальм н-ЖК в пище и экспрессии ферментов, гепатоциты формировали физиологичные олеиновые ТГ и олеиновые ЛП очень низкой плотности (ЛПОНП). Олеиновыми ТГ являются: олеил-олеил-олеат (ООО), олеил-олеил-пальмитат (ООП) и пальмитоил-олеил-пальмитат (ПОП) [12].

При избытке животной пищи и Пальм н-ЖК в инсулиннезависимых гепатоцитах содержание ее становится выше возможностей экспрессии генов стеароилдесатуразы и превращения Пальм н-ЖК в олеиновую моно-ЖК [13]. При этом клетки начинают формировать пальмитиновые ТГ типа олеил-пальмитоил-олеат (ОПО), олеил-пальмитоил-пальмитат (ОПП) и даже пальмитоилпальмитоил-пальмитат (ППП), трипальмитин [14].

За синтезом афизиологичных пальмитиновых ТГ следует: - формирование пальмитиновых ЛПОНП;

- нарушение поглощения клетками прелигандных ЛПОНП путем апоЕ/В-100 рецепторного эндоцитоза; - образование афизиологичных пальмитиновых ЛПНП;

- «замусоривание» межклеточной среды самыми малыми и плотными липопротеинами низкой плотности-4 (ЛПНП);

- нарушение биологической функции эндоэкологии;

- компенсаторная активация биологической реакции воспаления с целью восстановить «чистоту» межклеточной среды.

Усиление in vivo синтеза первичных и вторичных медиаторов биологической реакции воспаления, особенно С-реактивного белка (СРБ), создает условия для РИ. Высокое содержание в пище экзогенной Пальм н-ЖК является основным нарушением биологической функции трофологии и самым частым афизиологичным условием РИ при нарушении биологических функций трофологии и эндоэкологии.

При избытке в пище н-ЖК развивается феномен липотоксичности; в клетках Пальм н-ЖК в форме неэтерифицированной ЖК (НЭЖК) с альбумином (АЛБ), как и ГЛЮ, химически взаимодействует с белками (реакция пальмитоилирования), нарушая их функцию [15]. Для снижения липотоксичности Пальм н-ЖК в форме НЭЖК клетки этерифицируют ее в пальмитиновые ТГ. При этом токсичность НЭЖК сменяется токсичностью афизиологичных ТГ типа ППП, которые накапливаются в цитозоле всех инсулинзависимых клеток, включая и $\beta$-клетки островков Лангерганса [16]. Трипальмитат с температурой плавления $48^{\circ} \mathrm{C}$ не может гидролизовать ни одна липаза цитозоля [17]; в условиях липотоксичности ППП гепатоциты погибают по механизму апоптоза. Образовавшиеся тельца апоптоза «замусоривают» межклеточную среду, нарушают биологическую 
функции эндоэкологии и инициируют биологическую реакцию воспаления, которая и формирует условия РИ. Накопление ТГ типа ППП в гепатоцитах, как мы считаем, и есть причина развития неалкогольной жировой болезни печени (стеатоза), которая при развитии биологической реакции воспаления превращается в стеатогепатит.

При алиментарном дефиците ЭС поли-ЖК in vivo происходит нарушение синтеза аминофосфолипидов (фосфатидилсерина и фосфатидилэтаноламина), у которых в позиции sn-2 всегда этрифицированы $\omega-6$ арахидоновая или $\omega-3$-эйкозапентаеновая ЭС поли-ЖК [18]. Если в клеточной мембране из гидрофобных фосфатидилхолинов ГЛЮТ4 не окружены менее гидрофобными аннулярными ФЛ, транспортер не может совершать физиологичные конформационнные (пространственные) изменения формы молекулы [19] при переносе в клетку ГЛЮ, и его функция оказывается сниженной. ГЛЮТ4 функционирует как осциллятор; его канал всегда закрыт с одной из сторон, для чего ему постоянно приходится менять форму молекулы. При дефиците в клетках ЭС поли-ЖК РИ выражается в неспособности ИНС обеспечить физиологичную функцию ГЛЮТ4. ИНС может увеличить количество ГЛЮТ4 на мембране клеток, но активность дополнительных транспортеров будет низкой. Следует увеличить количество в пище ЭС поли-ЖК и обеспечить их биодоступность для энтероцитов. Алиментарный дефицит ЭС поли-ЖК развивается нечасто; основными источниками ЭС поли-ЖК в пище служат рыба и морепродукты ( $\omega-3$ ЭС поли-ЖК), куриные яйца и свиное сало-шпик ( $\omega-6$ ЭС поли-ЖК) [20]. Для уменьшения РИ при неалкогольной жировой болезни печени следует снизить потребление с пищей Пальм н-ЖК и увеличить количество олеиновой моно-ЖК, эссенциальной С 18:2 линолевой ненасыщенной (нена- ЖК), ЭС поли-ЖК, а также метионина и холина.

Атеросклероз - патология клеток in vivo; этиологию его составляет, по всей вероятности, дефицит в клетках ЭС поли-ЖК [21]. Патогенетической же основой чаще всего является избыточное содержание в пище Пальм н-ЖК, пальмитиновых ТГ и ЛПОНП. Нарушение метаболизма пальмитиновых ЛПОНП инициирует снижение поглощения клетками лигандных линолевых и линоленовых ЛПНП при апоВ-100-эндоцитозе, которые и переносят к клеткам ЭС поли-ЖК. Причиной снижения биодоступности линолевых и линоленовых ЛПНП и ЭС поли-ЖК для клеток оказывается нарушение превращения липидов в пальмитиновые ЛПОНП. Мы же расцениваем это как патологию ЛПНП, которая может быть вызвана разными причинами, хотя основная из них - нарушение биологической функции трофологии.

РИ формируется и при избыточном количестве в пище углеводов и ГЛЮ в инсулинзависимых гепатоцитах; при этом отработанной на ступенях филогенеза экспрессии генов стеароилдесатуразы оказывается недостаточно, чтобы превратить в олеиновую моно-ЖК все количество синтезированной из ГЛЮ in situ de novo Пальм н-ЖК и этерифицировать их в физиологичные олеиновые ТГ типа ООО, ООП и ПОП. В случае выраженного избытка субстрата и неадекватной активности ферментов происходит синтез не олеиновых ТГ типа ООО и ОПО, а только ПОП [22]. Гидролиз этих ТГ в крови в ЛПОНП постгепариновая липопротеинлипаза и ее кофактор апоС-II активируют в малой степени, и гидролиз ТГ типа ПОП происходит с низкой константой скорости реакции. Все это нарушает образование лигандных олеиновых ЛПОНП и их поглощение клетками путем апоЕ/В-100-рецепторного эндоцитоза. При этом в крови происходит накопление афизиологично самых больших ЛПнП-1 с высоким остаточным содержанием ТГ [23]. Они «замусоривают» межклеточную среду, нарушают биологическую функцию эндоэкологии и активируют биологическую реакцию воспаления; она же всегда создает условия РИ. Иногда гипертриглицеридемия бывает столь высокой, а гипергликемия - не столь значительной, что приходится дифференцировать первичную ГЛП фенотипа II б от диабета второго типа [24, 25]. Анализируя перенос ЖК в составе ЛП, можно решить, зависит ли это состояние от а) усиления индукции субстратом (перееданием) на фоне недостаточной экспрессии генов стеароилдесатуразы или б) врожденных нарушений протеинов переноса ЖК, уточняя при этом и причины РИ.

Условия для РИ формируют и врожденные нарушения биологической функции локомоции. Происходит это в ЛП, но не в ЛПНП, как мы обычно полагаем, а в ЛПОНП. ЛПНП и ЛПОНП - филогенетически разные системы переноса к клеткам ЖК в форме неполярных липидов и одним апоВ-100. ЛПНП сформировались на миллионы лет раньше, чем ЛПОНП, и они исполняют разные биологические функции, перечисленные ниже.

- Филогенетически ранние ЛПНП исполняют биологическую функцию гомеостаза и переносят к клеткам С 18:2 линолевую, С 18:3 линоленовую нена-ЖК в форме ТГ и ЭС поли-ЖК в форме эфиров ХС, обеспечивая клетки структурными материалами для построения мембран и субстратами для синтеза эйкозаноидов. Клетки поглощают ЛПНП путем апоВ-100-рецепторного эндоцитоза, и их ранняя функция не зависит от ИНС; патология же самих ЛПНП встречается редко.

- Филогенетически поздние ЛПОНП сформированы при действии ИНС с целью обеспечения субстратами энергии биологической функции локомоции; они переносят к клеткам только С 16:0 Пальм н-ЖК, С 18:0 стеариновую н-ЖК и С 18:1 олеиновую моноЖК - субстраты для $\beta$-окисления в митохондриях. Количество липидов в ЛПОНП на порядок выше, чем в ЛПНП нена-ЖК, и на два порядка больше необходимого количества ЭС поли-ЖК. Клетки поглощают олеиновые и пальмитиновые ЛПОНП путем иного апоЕ/В-100-рецепторного эндоцитоза; при этом плотность всех афизиологичных ЛПОНП в крови соответствует интервалу плотности ЛПНП.

Формирует РИ и изменение генотипа апоЕ, афизиологичные формы которого в популяции встречается намного чаще, чем мы обнаруживаем специфичную ГЛП фенотипа III. При генотипе $22 / e 2$ аффинность апоЕ/В-100-рецепторов к одноименному лиганду на поверхности ЛПОНП составляет $2 \%$ от нормы с развитием выраженной ГЛП и увеличением в плазме крови концентрации ЛПНП-1 (как при избытке в пище углеводов). Избыточная индукция углеводами и усиление синтеза олеиновых ТГ типа ПОП приводит к нарушению поглощения их клетками и «высвечивает» те врожденные нарушения, которые при умеренном питании могли бы оставаться «молчащими» многие годы. При этом нет нарушений в системе ИНС, но развитие ГЛП, нарушение биологической функции эндоэкологии и биологическая реакция воспаления блокируют регуляторное действие ИНС. Отметим, что при атеросклерозе развивается не диабет второго типа, а состояние РИ как следствие функционального нарушения биологической функции 
трофологии, биологической функции гомеостаза (внутриклеточного дефицита ЭС поли-ЖК) и функции ГЛЮТ4.

Нарушение биологической функции трофологии, алиментарный дефицит в пище необходимой для всех животных $\omega$-6 С 18:2 линолевой нена-ЖК, эссенциального метионина (холина) не дает возможности гепатоцитам включать экзогенную Пальм н-ЖК в состав фосфатидилхолинов и вынуждает гепатоциты синтезировать только ТГ, вплоть до ППП. Устранение дефицита в пище субстратов при одновременном снижении Пальм н-ЖК - и есть основа патогенетически обоснованного лечения неалкогольной жировой болезни печени, предотвращения гибели клеток по типу апоптоза, нарушения биологической функции эндоэкологии и формирования РИ [26]. Эту терапию можно дополнить гиполипидемической терапией агонистами рецепторов активации пролиферации пероксисом (фибраты и глитазоны) и бигуанидами [27].

Продолжается дискуссия и о роли в атероматозе интимы артерий эластического типа и в биологической реакции воспаления самой короткой из нена-ЖК у человека, $\omega-7$ С 16:1 пальмитолеиновой нена-ЖК. Среди продуктов питания самое высокое ее содержание - в говядине (7-8\% всех ЖК). Однако клетки организма коровы ее не синтезируют, $\omega-7-$ ЖК бактерий. Синтезирует ее масса бактерий в четырехкамерном желудке коровы, которые функционируют на условиях симбиоза и осуществляют гидролиз до ГЛЮ всей клетчатки. Корова поедает большое количество молодой травы, да и на сено траву скашивают до того, как происходит формирование семян. В растениях же ЖК содержат только семена, а в пище коровы их мало. Поэтому энтероциты коровы всасывают все те ЖК, которые высвобождаются при гибели микрофлоры. В коровьем молоке много короткоцепочечных ЖК - C4-масляной ЖК (бутирата) они и обусловливают как запах и вкус парного молока, так и особенность сливочного масла быстро становится прогорклым. Афизиологичную пальмитолеиновую ЖК окисляют ферменты пероксисом при оптимизации в гепатоцитах экзогенных ЖК [28].

Пальмитолеиновая моно-ЖК в пальмитиновых ТГ и ЛПОНП проявляет свойства н-ЖК; если их много, они вместе с Пальм и стеариновой н-ЖК способствуют формированию РИ [29]. Пальмитиновые ТГ типа ПОП обладают провоспалительной активностью, свойственной всем эндогенным флогогенам (инициаторам воспаления) как биологическому «мусору». Полагают, что при активации ИНС стеароилдесатураза-1 может повышать в составе ТГ и ЛПОНП содержание пальмитолеиновой моно-ЖК при десатурации Пальм н-ЖК как субстрата, и эту реакцию могут активировать пролифераторы пероксисом [30], в частности глитазоны. Вместе с тем содержание пальмитолеиновой моно-ЖК в ТГ не бывает высоким, и афизиологичное действие ее оказывается не столь значительным [31]. Следует признать, что молоко для взрослого человека по составу ЖК в ТГ является далеко не физиологичным продуктом; большая часть ЖК молока - это Пальм н-ЖК и короткоцепочечные ЖК при низком содержании нена-ЖК и отсутствии ЭС поли-ЖК. Все длинноцепочечные ЖК этерифицированы в пальмитиновые ТГ.

Инициирует РИ и большое количество в пище неснятого молока и продуктов, из него изготовленных. Высокая степень афизиологичности ЖК коровьего молока и его «конечных липидов» обусловлена высокой степенью биодоступности ЖК для новорожденного [32].
Материнское молоко - пища новорожденного, и у него для гидролиза пальмитиновых ТГ в кишечнике имеется специфичная липаза, экспрессия которой заканчивается в возрасте 1 года. После этого ТГ молока для ребенка становятся нефизиологичными. Молоко физиологично для постнатального питания в 1-й год жизни, но нельзя оставаться ребенком всю жизнь. Вместе с тем биология не давала согласия не превращение млекопитающих в млекопитающихся. Поэтому липиды молока, как и говядины, при высоком содержании Пальм н-ЖК и пальмитолеиновой моно-ЖК являются теми животными продуктами, которые несопоставимы с иной животной пищей по способности инициировать РИ [33]. В связи с этим имеет смысл убрать из диетологических рекомендаций постную телятину, состав ЖК в которой так же афизиологичен, как и в говядине. Основной причиной распространенных в популяции человека неинфекционных заболеваний, в том числе и состояние РИ, является нарушение биологической функции трофологии и биологической функции эндоэкологии. Добавление в молочные продукты пальмового масла еще более усугубляет проблему избыточного количества в пище Пальм н-ЖК. Столь же негативным является и замена в продуктах питания глюкозы на фруктозу [34].

Вторая причина РИ - нарушение биологической функции эндоэкологии и активация биологической реакции воспаления. Каковыми бы не были этиологические факторы нарушения «чистоты» межклеточной среды, «замусоривания» ее эндогенными флогогенами (инициаторами воспаления), экзогенными инфекционными патогенами, активация биологической функции воспаления, синтез первичных и вторичных маркеров синдрома системного воспалительного ответа всегда сформируют РИ. Наибольший вклад в это, по всей видимости, принадлежит вторичному медиатору биологической реакции воспаления, белку острой фазы СРБ. Мы полагаем, что СРБ исполняет единую биологическую роль: он является белком-вектором направленного переноса ЖК с целью обеспечения субстратами для наработки энергии клетками РСТ, которые реализуют биологическую реакцию воспаления. Все этапы данной биологической реакции сопряжены с затратами энергии. Это относится к нейтрофилам и физиологичной денатурации ими эндогенных флогогенов путем окисления активными формами $\mathrm{O}_{2}$ и фагоцитоза: это относится и к монослою эндотелия и биологической реакции трансцитоза - переносу биологического «мусора» в интиму артерий эластического типа из крови для последующей утилизации. Наиболее энергоемкой является функция оседлых макрофагов - утилизация в лизосомах биологического «мусора». СРБ активирует все клетки РСТ (интерстициальной ткани) путем усиленного обеспечения их субстратами для наработки энергии Пальм н-ЖК + олеиновой моно-ЖК в форме ТГ в составе ЛПОНП.

Особенностью СРБ является то, что белок функционально активен в форме мономера (пептид 25 кДа) и пентамера (молекулярная масса 125 кДа). СРБ-мономер имеет свойства иммуномодулятора; СРБ-пентамер является липидпереносящим белком-вектором. Особенность СРБ-пентамера - высокая его аффинность при связывании с лизофосфатидихолином; она на два порядка выше, чем при взаимодействии с иными ФЛ. Действие СРБ функционально связано с активностью фосфолипазы $\mathrm{A}_{2}$, которая после секреции ее в кровь также связывается с ЛПОНП [35]. Когда toll-рецепторы РСТ опре- 
деляют «замусоривание» межклеточной среды, действуя по принципу «свой - не свой» [36], фосфолипаза $\mathrm{A}_{2}$ гидролизует фосфатидилхолин в ЛПОНП [37] и образует лизофосфатидилхолин, с которым и связывается СРБ-пентамер. В физиологичных условиях СРБ в крови всегда ассоциирован с ЛПОНП. При активации биологической реакции воспаления молекулы СРБ перекрывают в ЛПОНП физиологичный апоЕ/В-100-лиганд, сами становятся патофизиологичным лигандом и переадресуют поток ЛПОНП к клеткам РСТ, которые непосредственно реализуют биологическую реакцию воспаления. Клетки же, в свою очередь, синтезируют и «выставляют» на мембрану рецепторы к СРБ+CD36, которые содержат CD36 - транслоказу для длинноцепочечных ЖK [38]. Формирование липидных пятен в интиме у детей при разном по этиологии воспалении и едином патогенезе является результатом действия СРБ; это функциональный липоидоз оседлых макрофагов интимы артерий. К ранним признакам атероматоза и пенистым клеткам липоидоз отношения не имеет.

При активации биологической реакции воспаления и специфичном действии СРБ все ИНС-зависимые миоциты оказываются на «голодном пайке»; в крови нет ЛПОНП, которые миоциты могут поглощать путем апоЕ/B-100-рецепторного эндоцитоза; клиническим признаком этого служит мышечная слабость и явления атаксии. При нарушении биологической функции гомеостаза активируется биологическая функция адаптации, усиливается биологическая реакция компенсации и активация секреции адреналина. ИНС активирует гормонзависимую липазу в инсулинзависимых и инсулиннезависимых адипоцитах и компенсаторно повышает в межклеточной среде содержание НЭЖК+АЛБ. Активация пассивного поглощения миоцитами НЭЖК по градиенту концентрации устраняет нарушение в миоцитах биологической функции гомеостаза, но одновременно останавливает и окисление ГЛЮ в митохондриях, формируя РИ. При этом:

- гормон не в силах повлиять на действие филогенетически более раннего адреналина;

- не может предотвратить повышение в межклеточной среде содержания НЭЖК;

- не может повлиять на блокаду окисления ГЛЮ в митохондриях в инсулинзависимых клетках с последующим развитием РИ, гипергликемией и гиперинсулинемией; а ведь все инсулинзависимые клетки ранее были инсулиннезависимыми, и действие адреналина стали реализовать за миллионы лет до начала синтеза ИНС.

Третья причина формирования синдрома РИ - нарушение биологической функции адаптации при действии на уровне паракринных сообществ филогенетически более ранних, чем ИНС, тиреоидных гормонов, гормона роста, катехоламинов, глюкокортикоидов и эстрогенов. Наиболее часто развивается РИ при беременности и гиперсекреции эстрогенов. То же происходит и при гиперфункции щитовидной железы и гиперсекреции тиреоидных гормонов, при акромегалии и усилении секреции гормона роста. Во всех случаях состояние РИ формируется по одной причине: активация гормонзависимой липазы (или липаз) в каждой из клеток или в локальной пуле интерстициальной ткани и увеличение в межклеточной среде содержания НЭЖК+АЛБ. Заметим, что адипоциты это тоже клетки РСТ, интерстициальной ткани, и они также за миллионы лет до появления ИНС реагировали на филогенетически ранние гормоны и повышение ими концентрации НЭЖК+АЛБ в межклеточной среде.

РИ в инсулинзависимых тканях проявляется по-разному.

- В инсулиннезависимых гепатоцитах - при избытке в пище экзогенной Пальм н-ЖК, низкая экспрессия гена стеароилдесатуразы и превращение в олеиновую моно-ЖК только части экзогенной Пальм н-ЖК, синтез пальмитиновых ТГ [39] и ЛПОНП, превращение их в афизиологичные пальмитиновые ЛПНП, блокада апоВ- 100-рецепторного поглощения клетками ЛПНП [40], «замусоривание» межклеточной среды малыми, плотными ЛПНП-4 с развитием биологической реакции воспаления; ИНС не может преодолеть действие филогенетически более раннего СРБ и липолитическую активность адреналина.

- В инсулинзависимых гепатоцитах - при избытке в пище углеводов и синтезе из ГЛЮ большого количества Пальм и стеариновой н-ЖК не происходит адекватной экспрессии гена (генов) стеароилдесатуразы; это вынуждает гепатоциты образовывать олеиновые ТГ типа ПОП, олеиновые ЛПОНП и афизиологичные олеиновые ЛПНП, инициирует блокаду апоВ-100-поглощения клетками ЛПНП и «замусоривание» межклеточной среды афизиологичными ЛПНП-1 с развитием биологической реакции воспаления и РИ.

- В миоцитах - это неспособность ИНС обеспечить физиологичную активность ГЛЮТ4 и усиление поглощения клетками ГЛЮ в период биологической реакции экзотрофии и постпрандиальной гипергликемии. При этом развивается гликопения цитозоля, происходит активация гликогенолиза и усиление глюконеогенеза в гепатоцитах с развитием гипергликемии в межклеточной среде и компенсаторной гиперинсулинемии [41].

- В адипоцитах - неспособность ИНС в ИНСзависимых клетках блокировать активность гормонзависимой липазы, гидролиз ТГ и выход в межклеточную среду НЭЖК+АЛБ при активации липазы в адипоцитах филогенетически более ранними тиреоидными гормонами, гормоном роста, глюкокортикоидами и эстрогенами.

Большинство авторов обоснованно считают основной причиной РИ повышение в межклеточной среде и плазме крови содержания НЭЖК+АЛБ [11]. В филогенезе поглощение клетками НЭЖК путем пассивной диффузии через полярный бислой липидов плазматической мембраны является если не первым, то, по крайней мере, ранним способом поглощения клетками ЖК в полярной форме [42], которое отработано еще на уровне паракринных сообществ клеток. Следует отметить, что жировые клетки являются филогенетически ранними компонентами РСТ, и гидролиз в них ТГ в рамках каждого сообщества регулируют филогенетически ранние гормоны-предшественники тиреоидных гормонов, катехоламинов и глюкокортикоидов [43]. Активное же поглощение клетками ЖК в форме неполярных пальмитиновых ТГ в составе ЛПОНП сформировалось в филогенезе более поздно. И много позже, при становлении биологической функции локомоции и системы ИНС, сформировались олеиновые ТГ и ЛПОНП, специфичный направленный перенос Пальм н-ЖК и олеиновой моно-ЖК к инсулинзависимым клеткам и их поглощение путем апоЕ/В-100- 
рецепторного эндоцитоза. Сформированные ИНС в рамках биологической функции локомоции олеиновые ЛПОНП являются в филогенетической цепочке последними, самыми производительными. Однако и их функция не лишена недостатков, которые составляют основу патогенеза иных нозологических форм заболеваний, в частности ожирения. В каких же функциональных отношениях находятся активное поглощение клетками ЖК в форме неполярных ТГ при рецепторном эндоцитозе и пассивное поглощение клетками ЖК в форме НЭЖК?

Различие двух вариантов поглощения клетками ЖК состоит в том, что:

- при пассивном поглощении ЖК в цитозоль поступают полярные НЭЖК, которые клетки сразу могут превратить в неполярную форму ацил-КоА, перенести через внутреннюю мембрану митохондрий и окислить; НЭЖК - активная форма ЖК;

- при апоЕ/В-100-рецепторном эндоцитозе клетки поглощают ЖК в форме неполярных ТГ, и окислить их сразу возможности нет; вначале запасенные ТГ надо гидролизовать под действием гормонзависимой липазы, которую в инсулинзависимых клетках ингибирует ИНС; гормон а) ингибирует липолиз и образование в клетках НЭЖК; б) активность карнитин-пальмитоил ацилтрансферазы и поглощение митохондриями НЭЖК; в) образование в клетках кетоновых тел; таким образом, лишая митохондрии возможности окислять ЖК, ИНС вынуждает их окислять ГЛЮ, способность ИНС усиливать окисление клетками ГЛЮ опосредована через регуляцию метаболизма ЖК.

Мобилизация ЖК в форме НЭЖК из РСТ (из адипоцитов), их пассивное поглощение клетками происходит с целью быстрого окисления в митохондриях и наработки АТФ. Активное рецепторное поглощение клетками ЖК в форме ТГ в составе ЛПОНП предполагает, в первую очередь, их депонирование и отсроченное использование, поэтому мобилизация ЖК из жировой ткани в форме НЭЖК+АЛБ происходит и в постпрандиальном периоде, если этого требует реализация биологической функции гомеостаза, эндо-экологии и биологической функции адаптации. И это ни в коей мере не зависит от активного поглощения клетками ЖК в форме ТГ и повышенной секреции ИНС. Можно полагать, что сформированная под действием ИНС система активного поглощения клетками ЖК в форме ТГ в составе ЛПОНП предназначена для снабжения субстратами энергии клеток только для биологической функции локомоции. В то же время, снабжение субстратами энергии клеток при реализации всех филогенетически ранних биологических функций происходит путем мобилизации ЖК из клеток РСТ, из адипоцитов в форме НЭЖК+АЛБ [44]. Поэтому содержание НЭЖК+АЛБ в сыворотке крови, увеличение содержания СРБ в субклиническом (клиническом) интервале, гипертриглицеридемию, повышение в плазме крови содержания тиреоидных гормонов, гормона роста, глюкокортикоидов и эстрогенов можно рассматривать как маркеры патофизиологичных состояний, которые формируют резистентность к ИНС $[45,46]$. Если в плазме крови повышено содержание СРБ, это можно рассматривать как тест РИ; к тому же, СРБ негативно соотносится с содержанием в плазме крови $\omega$-3 ЭС-поли-ЖК [47]. Уровень ХС в ЛП не помогает диагностике РИ [48]. Понять пути формирования РИ поможет определение в плазме крови ЖК, содержания Пальм н-ЖК и олеи- новой моно-ЖК [49], а также индивидуальных пальмитиновых и олеиновых ТГ [50]. При активации аутоиммунного процесса возможно и формирование антител как к ИНС, так и к его рецепторам.

Реализуя биологическую роль, ИНС обеспечивает субстратами энергии биологической функции локомоции и в физиологичной регуляции базальных процессов метаболизма регуляторного влияния не оказывает. Гормон в инсулинзависимых клетках:

- активирует пассивное поглощение клетками ГЛЮ путем «выставления» на мембрану дополнительного количества ГЛЮТ4;

- активирует запасание ГЛЮ путем синтеза гликогена;

- активирует окисление ГЛЮ в митохондриях путем блокады липолиза в ИНС-зависимых адипоцитах, понижение содержания НЭЖК в клетках и межклеточной среде; ИНС вынуждает митохондрии клеток окислять ГЛЮ, лишая их возможности окислять всегда предпочитаемые ими ЖК и кетоновые тела;

- активирует липогенез - синтез из экзо- и эндогенной ГЛЮ Пальм н-ЖК in situ de novo;

- активирует пальмитоилэлонгазу, превращает С 16:0 Пальм н-ЖК в С 18:0 стеариновую н-ЖК;

- наконец, активирует стеароилдесатуразу, усиливает превращение стеариновой н-ЖК в $\omega-9$ С-18:1 олеиновую моно-ЖК.

И вся активность ИНС может быть блокирована действием филогенетически более ранних гуморальных медиаторов на уровне паракринных сообществ клеток. Патогенез РИ сходен с механизмами становления in vivo эсссенциальной артериальной гипертензии; основа этих состояний - несоответствие действия гуморальной регуляции физиологичных процессов на уровне паракринных сообществ клеток и организма в целом.

РИ, мы полагаем, является филогенетически обусловленным интегральным патофизиологичным состоянием, которое вызвано нарушением биологических функций и активацией in vivo биологических реакций, формирование которых в филогенезе произошло ранее биологической функции локомоции и системы ИНС. Реализация каждой из биологических функций и реакций требует затрат энергии; для этого клетки поглощают Пальм н-ЖК и олеиновую моно-ЖК филогенетически ранним, пассивными способом диффузии НЭЖК из комплексов НЭЖК+АЛБ в плазматическую мембрану. При этом НЭЖК и кетоновые тела блокируют функцию ИНС на клеточном уровне. Однако не столь просто реализовать лечение РИ. В клинической практике рациональным будет установить, нарушение какой из биологических функций первично формирует условия для РИ, и использовать все возможности для ее нормализации. Это в первую очередь относится к биологической функции трофологии, функции гомеостаза, биологической функции эндоэкологии и биологической реакции воспаления, а также биологической функции адаптации и биологической реакции компенсации. И не всегда просто разобраться в причинах нарушения биологических функций и устранить те экзо- или эндогенные условия, которые инициируют активацию биологических реакций, которые, не имея непосредственного отношения к системе ИНС, формируют афизиологичное функциональное (регуляторное) состояние РИ. В то же время, если состояние РИ обусловлено нарушениями в первичной структуре многочисленных белков в системе ИНС, то это, как мы полагаем, сахарный диабет второго типа. 


\section{REFERENCES}

1. Balabolkin M.I., Klebanova E.M., Kreminskaya V.M. Lechenie saharnogo diabeta i ego oslozhnenij (ruk. dlya vrachej). M.: $O A O$ «Izd-vo «Medicina». 2005. $512 \mathrm{~s}$.

2. Majorov A.Yu. Insulinorezistentnost' v patogeneze saharnogo diabeta 2 tipa. Voprosy patogeneza. 2011; 1: 35-43.

3. Shestakova M.V., Breskina O.Yu. Insulinorezistentnost': patofiziologiya, klinicheskie proyavleniya, podhody k lecheniyu. Consilium. Med. 2002; 4 (10).

4. Annuzzi G., De Natale C., Iovine C. et al. Insulin resistance is independently associated with postprandial alterations of triglyceriderich lipoproteins in type 2 diabetes mellitus. Arterioscler. Thromb. Vasc. Biol. 2004; 24: 2397-2402.

5. Taskinen M.R., Adiels M., Westerbacka J. et al. Dual metabolic defects are reguired to produce hypertriglyceridemia in obese subjects. Arterioscler. Thromb. Vasc. Biol. 2011; 31 (9): 2144-2150.

6. Riccardi G., Giacco R., Rivellesse A.A. Dietary fat, inslin sensitivity and the metabolic syndrome. Clin. Nutr. 2004; 23 (4): 447-456.

7. Gof D.C., D’Agostine R.B., Haffner S.M., Otvos J.D. Insulin resistance and adiposity influence lipoprotein size and subclass concentrations. Results from the insulin resistance atherosclerosis study. Metabolism. 2005; 54 (2): 264-270.

8. Stein L.L., Dong M.H., Loomba R. Insulin sensitizers in nonalcoholic fatty liver disease and steatohepatitis: Current steatus. Adv. Ther. 2009; 26 (10): 893-907.

9. Li L., Yang G., L G., Tang Y., Li K. High-fat- and lipid-induced insulin resistance in rats: he comparison of glucose metabolism, plasma resistin and adiponectin levels. Ann Nutr. Metab. 2006; 50 (6): 499-505.

10. Titov V.N. Toriya biologicheskih funkcij i ee primenenie pri vyyasnenii patogeneza rasprostranennyh zabolevanij cheloveka. Uspehi sovr. biol. 2008; 128 (5): 435-452.

11. Roden M. How free fatty acids inhibit glucose utilization in human skeletal muscle. New. Physiol. Sci. 2004; 19: 92-96.

12. Malone M., Evans J.J. Determining the relative amounts of positional isomers in complex mixtures of triglycerides using reversedphase high-performance liguid chromatography-tandem mass spectrometry. Lipids. 2004; 39 (3): 273-284.

13. Bysted A., Helmer G., Lund P. Et al. Effect of dietary fatty acids on the postprandial fatty acid composition of triacylglycerol-rich lipoproteins in healthy male subjects. Eur. J. Clin. Nur. 2005; 59 (1): 24-34.

14. Bracco U. Effect of triglyceride structure on fat absorption ${ }^{1-3}$. Am. J. Clin. Nur. 1994; 60: 1002-1009.

15. Malhi H., Goes G.J. Molecular mechanisms of lipotoxicity in nonalcoholic fatty liver disease. Semin. Liver. Dis. 200828 (4): $360-369$.

16. Oakes N.D., Furler S.M. Evaluation of free fatty acid metabolism in vivo. Ann. N.Y. Acad. Sci. 2002; 967: 158-175.

17. Reid B.N., Ables G.P., Otlivanchik O.A. et al. Hepatic overexpresion o hormone-sensitive lipase and adipose triglyceride lipase promotes fatty acid oxidation, stimulates direct release of free fatty acids, and ameliorates steatosis. J. Biol. Chem. 2008; 283 (19): 13087-13099.

18. Fragiskos B., Chan A.C., Choy P.C. Competition of n-3 and n-6 polyunsaturated fatty acids in the isolated perfused rat heart. Ann. Nutr. Metab. 1986; 30 (5): 331-334.

19. Ivanov A.S. Osnovnye principy konformacionnogo raznoobraziya belkov dlya mediko-biologov. Biomed. himiya. 2011; 57 (1): 31-60.

20. Bermudez B., Lopez S., Ortega A. et al. Oleic acid in olive oil: from a metabolic framework toward a clinical perspective. Curr. Pharm. Des. 2011; 17 (8): 831-843.

21. Titov V.N. Ateroskleroz - problema obschej biologii: narushenie biologicheskih funkcij pitaniya i ‘endo`ekologii. Uspehi sovr. biol. 2009; 129 (2): 124-143.
22. Berry S.E. Triacylglycerol structure and interesterificaton of palmitic and stearic acid-rich fats: an overview and implications for cardiovascular disease. Nutr. Res. Rev. 2009; 22 (1): 3-17.

23. Tremblay A.J., Despres J.P., Riche M.E. et al. Associations between the fatty acid content of triglyceride, visceral adipose tissue accumulation, and components of he insulin resistance syndrome. Metabolism. 2004; 53 (3): 310-317.

24. Rozhkova T.A., Amelyushkina V.A., Yarovaya E.B., Malyshev P.P., Titov V.N. Kliniko-laboratornoe vyyavlenie fenotipicheskih osobennostej u pacientov s vysokoj gipertrigliceridemiej. Klin. lab. diagnostika. 2011; 5: 10-16

25. Teng K.T., Nagapan G., Cheng H.M., Nesaretnam K. Palm olein ad olive oil cause a higher increase in postprandial lipemia compared with lard but had no effect on plasma glucose, insulin and adipocytokines. Lipids. 2011; 46 (4): 381-388.

26. Sakurai M, Takamura T., Ota T. et al. Liver steatosis, but not fibrosis, is associated with insulin resistance in nonalcoholic fatty liver disease. J. Gastroenterol. 2007; 42 (4): 312-317.

27. Huang Y., Fu J.F., Shi H.B., Liu L.R. Metabolism prevents nonalcoholic fatty liver disease in rats: role of phospholipase A2/lysophosphatidylcholine lipoapoptosis pathway in hepatocytes. Zhonghua. Er. Ke. Za. Zhi. 2011; 49 (2): 139-145.

28. Feldstein A.E., Lopez R., Tamimi T.A. et al. Mass spectrometric profiling of oxidized lipid products in human nonalcoholic fatty liver disease and nonalcoholic steatohepatitis. J. Lipid. Esp. 2010; 51 (10): 3046-3054.

29. Hal D., Poussin C., Velagapudi V.R. et al. Peroxisomal and microsomal lipid pathways associated with resistance to hepatic steatosis and reduced pro-inflammatory state. J. Biol. Chem. 2010; 285 (40): 31011-31023.

30. Kuda O., Stankova B., Tvrzicka E. et al. prominent role of liver n elevated plasma palmitoleate levels in response to rosiglitazone in mice fed high-fat diet. J. Physiol. Pharmacol. 2009; 60 (4): 135-140.

31. Fabbrini E., Magkos F., Su X. et al. Insulin sensitivity is not associated with palmitoleate availability in obese humans. J. Lipid. Res. 2011. 52 (4): 808-812.

32. Hunter J.E. Studies on effects of dietary fatty acids as related to their position on triglycerides. Lipids. 2001; 36 (7): 655-668.

33. Macfarlane D.P., Zou X., Andrew R. et al. Metabolic pathways promoting intrahepatic fatty acid accumulation in methionine and choine deficiency: implications for he pathogenesis of steatohhepatits. Am. J. Physiol. Endocrinol. Metab. 2011; 300 (2): 402-409.

34. Lim J.S., Mietus-Snyder M., Valente A. et al. The role of fructose in the pathogenesis of NAFLD an he metabolic syndrome. Nat. Rev. Gastroenterol. Hepatol. 2010; 7 (5): 251-264.

35. Titov V.N. Insulin - gumoral'nyj faktor obespecheniya ‘energiej biologicheskoj funkcii lokomocii. Vestnik RAMN. 2005; 2: 3-8.

36. Fessler M.B., Ruel L.L., Brown M. Tol-like receptor signaling links dietary fatty acids to the metabolic syndrome. Curr. Opin Lipidol. 2009; 20 (5): 379-385.

37. Han M.S., Park S.Y., Shinzawa K. et al. Lysophosphatidylcholine as a death effector in he lipoapoptosis of hepatocytes. J. Lipid. Res. 2008; 49 (1): 84-97.

38. Guthmann F., Haupt R., Looman A.C. et al. Fatty acid translocase/ CD36 mediaes the uptake of palmitate by type II pneumocytes. Am. Physiol. Soc. 1999; 277: 191-196.

39. Momchilowa S., Tsuji K., Itabashi Y. et al. Resolution of triacylglycerol positional isomers by reversed-phase high-performance liguid chromatography. J. Sep. Sci. 2004; 27 (12): 1033-1036.

40. Heath R.B., Karpe F., Milne R.W. et al. Selective portioning of dietary fatty acids into the VLDL TG pool In the early postprandial period. J. Lipid. Res. 2003; 44 (11): 2065-2072.

41. Liu J., Jahn L.A., Fowler D.E. et al. Free fatty acids induce insulin resistance $\mathrm{n}$ both cardiac and skeletal muscle microvaculature in humans. J. Clin. Endocrinol. Metab. 2011; 96 (2): 438-446. 
42. Baajaj M., Suraamornkul S., Kashyap S., et al. Sustained reduction in plasma free fatty acid concentration improves insulin action without altering plasma adipocytokine levels $\mathrm{n}$ subjects with strong family history of type 2 diabetes. J. Clin. Endocrinol. Metab. 2004; 89 (9): 4649-4655.

43. Radesky J.S., Oken E., Rifas-Shiman S.L. et al. Diet during early pregnancy and development of gestational diabetes. Paediatr. Perinat. Epidemiol. 2008; 22 (10): 47-59.

44. Lewis G.F., Steiner G. Acute effects of insulin in the control of VLDL production in humans. Implications for the insulin-resistant state. Diabetes. Care. 1996; 19 (4) 390-393.

45. Woodward M., Tunstall-Pedoe H., Batty G.D. et al. The prognostic value of adipose tissue fatty acids for incident cardiovascular disease: results from 3944 subjects in the Scottish Heart Health Extended Cohort Study. Eur Heart. J. 2011; 32 (11): $1416-1423$
46. Marinou K., Adiels M., Hodson L. et al. Young women partition fatty acids towards ketone body production rather than VLDL-TAG synthesis, compared with young men. Br. J. Nutr. 2011; 105 (6): 857-865.

47. Micallef M.A., Munro I.A., Gag M.L. An. Inverse relationship between plasma n-3 fatty acids and C-reactive protein in healthy individuals. Eur. J. Clin. Nutr. 2009; 63 (9): 1154-1156.

48. Kim-Dorner S.J., Deuster P.A. Zeno S.A. et al. Should triglycerides to high-density lipoprotein cholesterol ratio be used as surrogates for insulin resistance? Metabolism. 2010; 59 (2): 299-304.

49. Berry S.E., Miller G.J., Sanders T.A. The solid fat content of stearic acid-rich fats determines their postprandial effects. Am. J. Clin. Nutr. 2007; 85 (6): 1486-1494.

50. Paik M.J., Kim H., Lee J. et al. Separation of triacylglycerols and free fatty acids in microalgal lipids by solid-phase extraction for separate fatty acid profiling analysis by gas chromatography. J. Chromatogr. A. 2009; 1216 (31): 5917-5923.

\section{КОНТАКТНАЯ ИНФОРМАЦИЯ}

Титов Владимир Николаевич, доктор медицинских наук, профессор, руководитель лаборатории клинической биохимии липидов и липопротеинов ФГБУ «Российский кардиологический научно-производственный комплекс» Минздравсоцразвития России

Адрес: 122551, Москва, ул. 3-я Черепковская, д. 15а

Тел.: (495) 414-63-10

E-mail: vn_titov@mail.ru 